\title{
Spontaneous pneumomediastinum: a complication of anorexia
} nervosa?

\author{
R.J.Fergusson, T.R.D. Shaw and C.M. Turnbull \\ Western General Hospital, Crewe Road, Edinburgh EH4 2XU, UK.
}

\begin{abstract}
Summary: We describe a patient with anorexia nervosa who developed a spontaneous pneumomediastinum. Five other patients have been reported with this association, suggesting that tissue changes in anorexia nervosa may predispose to this condition.
\end{abstract}

\section{Introduction}

Spontaneous pneumomediastinum is an uncommon condition in which free air enters the mediastinum, usually from a leak at alveolar level (Macklin \& Macklin 1944; Schulman et al., 1982). It occurs in situations where there is a sudden increase in intraalveolar pressure such as severe coughing, straining and vomiting and has been associated with acute asthma (Kirsh \& Orvald, 1970), violent exercise (Morgan \& Henderson, 1981), diabetic ketoacidosis (Girard et al., 1971), marihuana smoking (Miller \& Spiekerman, 1972) and childbirth (Bradfass \& Martinez, 1976). We report a patient who developed a spontaneous pneumomediastinum in association with anorexia nervosa.

\section{Case report}

A 16 year old schoolgirl, who had had anorexia nervosa for 3 years, was admitted with a $2 \mathrm{~d}$ history of retrosternal chest pain. The pain radiated to the left shoulder and back and was worsened by swallowing and movement. She was extremely cachectic (weight $32 \mathrm{~kg}$ ) and had all the external features characteristic of anorexia nervosa. Her extremities were cold and cyanosed, and her pulse rate markedly reduced at 22 beats/min (Figure 1). Her blood pressure was $80 /$ $50 \mathrm{~mm} \mathrm{Hg}$ and the rectal temperature $34^{\circ} \mathrm{C}$. Subcutaneous emphysema was detectable in both supraclavicular fossae. On auscultation of the praecordium

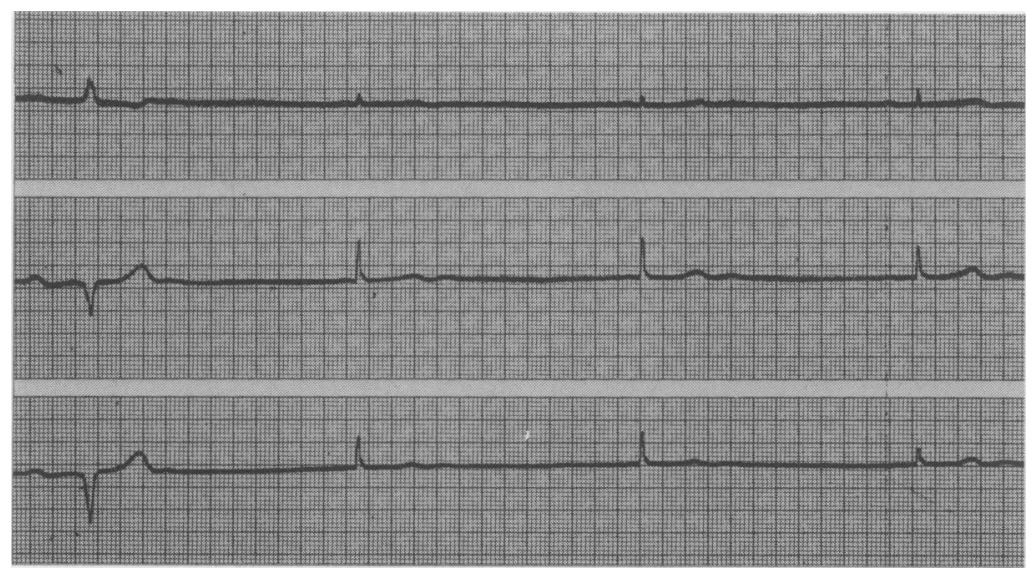

Figure 1 Electrocardiogram (rhythm strip) on admission showing marked sinus bradycardia.

Correspondence: R.J. Fergusson, M.B., M.R.C.P., Cardiac Unit, Western General Hospital, Crewe Road, Edinburgh EH4 2XU, UK.

Accepted: 7 February 1985 
there was a rasping sound coincident with each systole. A chest radiograph confirmed air in the mediastinum and the subcutaneous tissues of the neck (Figure 2). A plain abdominal film (Figure 3) showed air tracking down through the aortic opening in the diaphragm. A gastrograffin swallow showed no evidence of an oesophageal leak. The white blood count and erythrocyte sedimentation rate (ESR) were normal. The blood glucose was low at $2.8 \mathrm{mmol} / \mathrm{l}$, blood urea elevated at $12.5 \mathrm{mmol} / \mathrm{l}$ with a normal serum creatinine.

Intravenous fluids, atropine and dopamine were given and after $72 \mathrm{~h}$ the pulse rate, blood pressure and temperature became normal. The chest pain subsided within $48 \mathrm{~h}$ and the interstitial air on the chest radiograph resolved over the following week. The patient and her parents said there had been no spontaneous or induced vomiting before admission and no episodes of vomiting were seen during her stay in hospital.

\section{Discussion}

Spontaneous pneumomediastinum has been reported in five other patients suffering from anorexia nervosa (Al-Mufty \& Bevan 1977; Donley \& Kemple, 1978; Brooks \& Martyn, 1979; Altmeyer \& Morgan, 1981) including another case (Brooks \& Martyn, 1979) seen earlier at the Western General Hospital. In all cases the air leak closed spontaneously and only a short period of observation was required.

Sinus bradycardia and hypotension have been reported in patients with anorexia nervosa. The mean

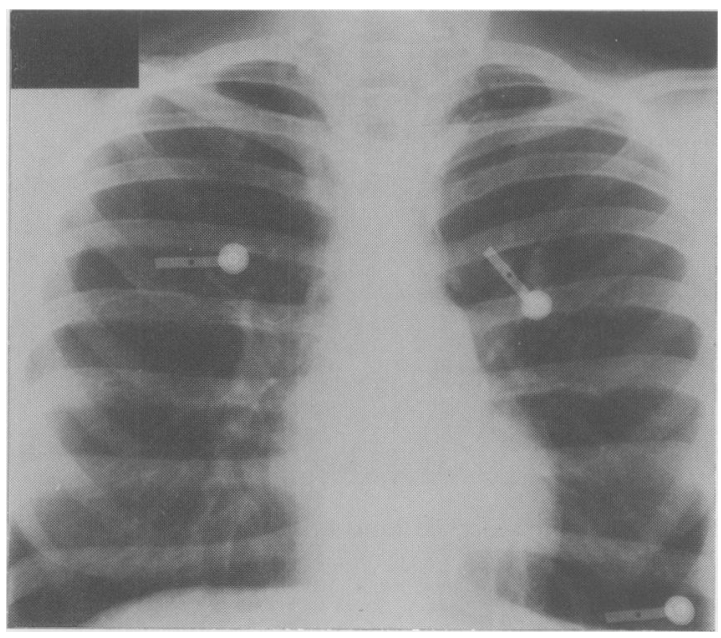

Figure 2 PA chest radiograph on admission showing air in the mediastinum and subcutaneous tissues of the neck.

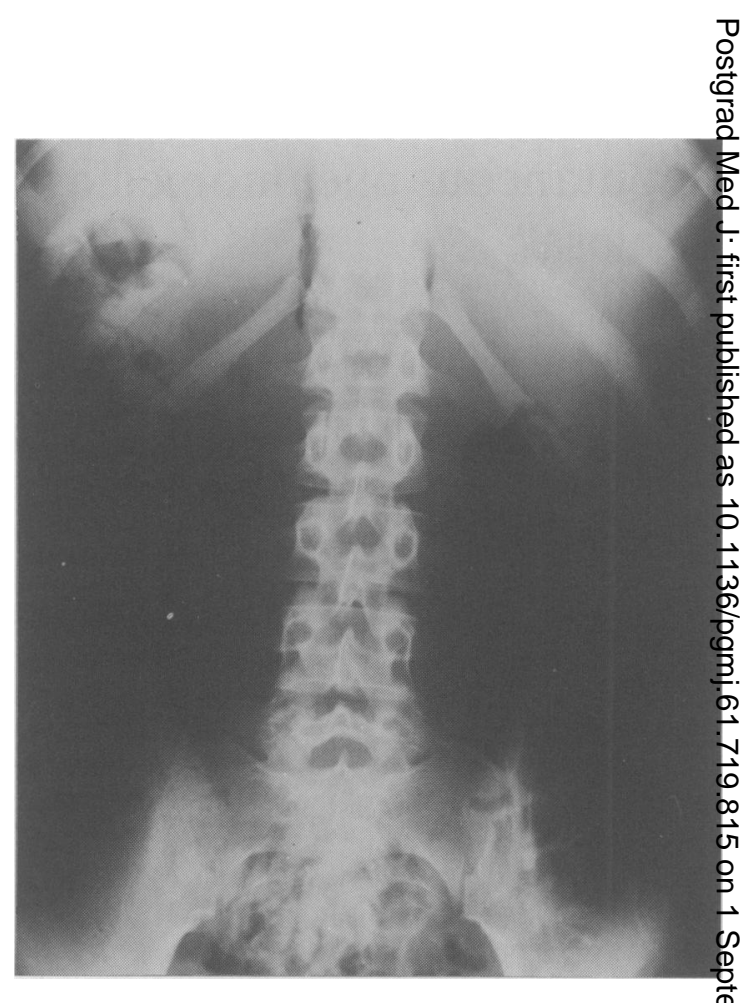

Figure 3 PA abdominal radiograph on admission showing air in the paravertebral gutter at a level of the aortic opening of the diaphragm.

heart rate and supine systolic blood pressure in $\overline{\mathrm{q}} \mathrm{F}$ patients with functional anorexia described by Gott응 diener et al. (1978) were 79 beats/min (range 60-92) and $87 \mathrm{mmHg}$ (range $70-107)$ respectively. The auth ors attributed these abnormalities to the markedp autonomic dysfunction demonstrated in theiס subjects. Our patient had a more marked bradycardia (Figure 1) which responded rapidly to intravenous atropine. It may be that her concomitant hypothermia? $\left(34^{\circ} \mathrm{C}\right)$ was contributing to the extreme slowness of he? pulse.

Tracking of air downwards from the mediastinum? through the hiatuses of the diaphragm to the ex traperitoneal space has been described in patients with spontaneous pneumomediastinum (Schulman et al. $\mathrm{\rho}$ 1982) including one case associated with anorexia $₹$ nervosa (Al-Mufty \& Bevan, 1977). It occurred in our patient (Figure 3) and was not associated with any abdominal symptoms or signs. A gastrograffin swallow showed no evidence of a perforation in the upper gastrointestinal tract and the air resolved spontaneously. When a spontaneous pneumomediastinum is not suspected the presence of free gas below thew diaphragm may cause some confusion and delay in making the correct diagnosis. In one case associatedo with anorexia nervosa (Al-Mufty \& Bevan, 1977) a perforated abdominal viscus was suspected and the $e^{-}$ patient underwent laparotomy. 
The exact link between anorexia nervosa and spontaneous pneumomediastinum is unclear. Self-induced vomiting is common in anorexia nervosa and is a recognized factor in the causation of spontaneous pneumomediastinum (Zegal \& Miller, 1979), but in only 2 of the 6 patients described has vomiting been known to precede the development of air in the mediastinum. Animal studies have shown that prolonged starvation causes a decrease in tissue elasticity in

\section{References}

AL-MUFTY, N.S. \& BEVAN, D.H. (1977). A case of subcutaneous emphysema, pneumomediastinum and pneumoretroperitoneum associated with functional anorexia. British Journal of Clinical Practice, 31, 160.

ALTMEYER, R.B. \& MORGAN, E.J. (1981). Spontaneous pneumomediastinum as a complication of anorexia nervosa. West Virginia Medical Journal, 77, 189.

BRADFASS, R.T. \& MARTINEZ, D.M. (1976). Mediastinal and subcutaneous emphysema in labour. Southern Medical Journal, 69, 1554.

BROOKS, A.P. \& MARTYN, C. (1979). Pneumomediastinum in anorexia nervosa. British Medical Journal, i, 125.

DONLEY, A.J. \& KEMPLE, T.J. (1978). Spontaneous pneumomediastinum complicating anorexia nervosa. British Medical Journal, ii, 1604.

GIRARD, D.E., CARLSON, V., NATULSON, E.A. \& FRED, H.L. (1971). Pneumomediastinum in diabetic ketoacidosis. Chest, 60, 455.

GOTTDIENER, J.S., GROSS, H.A., HENRY, W.L., BORER, J.S. \& EBERT, M.H. (1978). Effects of sef-induced starvation on cardiac size and function in anorexia nervosa. Circulation, $58,425$.

KIRSH, M.M. \& ORVALD, T.O. (1970). Mediastinal and the lungs (Sahebjami et al., 1978) and this may be a more significant factor in the development of an alveolar leak in these patients.

Spontaneous mediastinum in anorexia nervosa appears to be a benign condition and our case provides further evidence that no invasive investigations or detailed treatment are required and that after a short period of observation nutritional rehabilitation can commence.

subcutaneous emphysema complicating acute bronchial asthma. Chest, 57, 580 .

MACKLIN, M.I. \& MACKLIN, C.C. (1944). Malignant interstitial emphysema of the lungs and mediastinum as an important occult complication in many respiratory diseases and other conditions. Medicine (Baltimore), 23, 281.

MILLER, W.E. \& SPIEKERMAN, R.E. (1972). Pneumomediastinum resulting from performing Valsalva maneuvers during marihuana smoking. Chest, 62, 233.

MORGAN, E.J. \& HENDERSON, D.A. (1981). Pneumomediastinum as a complication of athletic competition. Thorax, 36, 155.

SAHEBJAMI, H., VASSALLO, C.L. \& WIRMAN, J.A. (1978). Lung mechanics and ultrastructure in prolonged starvation. American Review of Respiratory Diseases, 117, 77.

SCHULMAN, A., FATAAR, S., VAN DER SPUY, J.W., MORTON, P.C.G. \& CROSIER, J.H. (1982). Air in unusual places: some causes and ramifications of pneumomediastinum. Clinical Radiology, 33, 301.

ZEGAL, H.G. \& MILLER, W.T. (1979). Subcutaneous emphysema in a young man. Journal of the American Medical Association, 241, 1273. 